\title{
The Educational Management of Colleges and Universities Under the New Situation
}

\author{
Xu WANG \\ Tianjin University of Finance and Economics, \\ No.25 Zhujiang Road, Hexi District, Tianjin, China \\ e-mail: wangxu587@126.com
}

\begin{abstract}
Higher education is in an era of rapidly changing educational concepts, in the fierce competition for talent, the development of colleges and universities is facing enormous challenges and challenges. In a crisis and challenges of the environment, higher education must keep pace with the times, set foot on the road of reform of higher education, the use of new ideas to reform the educational management system of university management, the university management mechanism to keep up with the needs of social development.
\end{abstract}

Keywords-innovation; reform; education management

\section{INTRODUCTION}

In recent years, with the expansion of university enrollment, a substantial increase in the number of students, many colleges and universities appeared in the graduates' employment problem, these problems besides the environment, the great degree and the existing university education management mode, management mode and social human development needs, to a certain extent affect the University the development of. Thus it can be seen that the reform and innovation of the management mechanism in Colleges and universities is imperative. Innovation is the driving force for the development of all things, how to adapt to the development of the times and cultivate the innovative talents needed by the society is a difficult problem.

\section{The Present Situation And Problems of Higher EDUCATION MANAGEMENT}

\section{A. Management System is Not Perfect, Affect the Enthusiasm of Teachers and Students}

Due to the impact of the concept and the traditional mode of university administrative system is in the management of students, for students in education counseling work is not in place, these will affect the students' learning initiative and enthusiasm for practice and innovation makes students not to think in the. At the same time, in the management of teachers is also lack of scientific and reasonable, such as the evaluation system is not perfect, it is difficult to stimulate the enthusiasm of a good class teacher.

\section{B. The Content of Educational Management System is Old and the Teaching Effect is Not Good}

Early management of higher education by the national plans and arrangements, used to arrange the work of education and teaching according to the needs of the country and the instruction, and draw the management mode for the traditional administrative management mode, these caused a lot of drawbacks, such as arrangement and teaching settings no characteristics, they are led to the teaching mode and content of the stiff the teacher class program, there is no enthusiasm, can not effectively enhance the overall efficiency of education management.

\section{Management means a single, not humane}

In most colleges and universities, the traditional teaching methods are still used, and the collection of new information and new knowledge is seriously lagging behind. For example, in the teaching of required courses and elective courses between the proportion of students can not learn courses of interest, learning life rigid credit scoring method; defect, system setting unreasonable, these are the cause of higher education management is difficult to obtain good effect in the teaching work.

\section{College Education Management Problems AND INNOVATION}

\section{A. Educational Management Philosophy to Adapt to the Changing Times}

The management of colleges and universities needs to have a substantial breakthrough, first of all to achieve their own way of thinking innovation. Adapt to the new era of knowledge economy and the new concept of education management, the work of a new position, especially for the traditional shackles of efforts to establish a scientific and rational, with the times management philosophy. From the perspective of students, pay attention to the personalized development of their learning initiative, stimulate students to create a good learning atmosphere, to humanized management as the starting point to carry out the education management work, and constantly enrich the content of education management concept, lay the foundation for the later period system.

\section{B. Innovation of Educational Management System}

On the education management system to adhere to reform and update the system, it is particularly important, it can make scientific and reasonable work information becomes clear and evidence-based, innovation and reform the management system of education must be conducive to the education management. In the process of reform and innovation, the key is decentralized management, so that 
each part of the school planning work, clear their responsibilities of various departments, through the establishment of different system, so that the overall education become orderly. For example, Academy of Fine Arts students need creativity and inspiration, law school students need more rigorous and code. For different colleges and universities to set up different education management system will be more scientific, more acceptable to teachers and students, improve teaching quality.

\section{Reform and Innovation of Educational Evaluation System}

The management of college education, the reform of the old system, the implementation of a more scientific and rational management system, which requires schools to optimize the allocation of teaching resources, the management of the students more humane, to create more space for the. To adopt a variety of teaching methods to enrich the teaching curriculum, college education management evaluation system is not scientific and reasonable, directly related to the actual teaching results. Therefore, in order to stimulate the creative potential of teachers and students, we must start with the evaluation system.

\section{Educational Management Content}

First of all, from the ideological and moral quality and quality of Ideological and political theory courses, and participate in extracurricular practice base, so that the organic combination of theory and practice. Secondly, according to the social development needs to choose talents more suitable teaching materials, make diversified and personalized teaching, let students graduate with enterprise talent demand, and enthusiasm for learning and innovation consciousness of students.

\section{E. Professional Management Team}

The implementation of the work can not be separated from the implementation and promotion of personnel, so we should ask colleges and universities to improve the professional quality of education management staff. With it, managers should build a strong modern education management concept, and essence from traditional education idea, to its dregs, strengthen the idea of humanized management, give students more care and understanding, encourage the development of personalized. In addition, college administrators should have good occupation accomplishment, with a strong comprehensive management ability, to coordinate various communication problems, but also regularly organize training schools, strengthen business ability, strengthen the construction of education management team.

\section{College Education Management Big Data THINKING METHOD AND PRACTICE}

\section{A. The Logic of the Implementation of Educational Data Management Action}

In the era of big data applications ubiquitous data, with big data oriented thinking, the construction of intelligent education management, it should be said that the best goal of education management. In order to speed up the process of modernization of educational management and governance, it is necessary to carry out the planning of the implementation of the big data management system. From a structural point of view, education management consists of four elements: subject, object, goal, resources, and so on. The educational cloud is an important chain that connects the four elements. Cloud thinking is the top level of educational data, teachers, teaching and students are at the bottom of the educational data, data management is in the main body and the object, in order to achieve the goal and the allocation of resources and achieve. Therefore, in the process of data management of large data, it is necessary to promote the practice of three layers of action line. The first is the construction of the database of the top management of large data - the regional and full network of education cloud

At the same time, the establishment of distributed data centers in Colleges and universities to build a database add database add data model, the formation of data technology and educational resources on the coupling, as a college education management hardware support. Secondly, the construction of the basic data collection (mobile terminal applications), as well as a series of related data generated in the process of education statistics, upload, or a simple comb. Finally, in the middle layer is the construction of large data management operating system, mass data analysis, modeling and processing.

The three constitute a gradient relationship from the logical behavior, in reality, it is indispensable to promote the application of large data sharing relationship.

\section{B. According to the Data, It Can be Used to Manage the Integration of Thinking and Education}

On the whole, big data applications to education management provides the open management of external conditions, compared with the traditional bureaucratic compartmentalization, management, change the information asymmetry and flattening management trend of the original, and become interdependent and share information network model. The design of educational management decision only from top-level planning, analysis of pay more attention to the underlying data source in education, can even interact with the teaching staff and students, to get a lot of flow and generate data as a decision-making reference.

Therefore, in the process of education and teaching, it is very important to collect the original data. Usually, training and personnel training mode, the education management and teaching staff to master data related knowledge, ability so as to improve the ability of integration of the education information management and the data behind the value of 
exploration and accurate decision-making, in order to provide education for everyone can manage related data resources or feedback, to achieve intelligent education the top and bottom of the form of management decision of interaction. In college students' evaluation as an example, through the data collection and tracking with the reduction of College Students' actions, such as student individual experience in college, academic activities, social skills, values and moral performance data, the various types of data integration for the individual factors of the learning process"

Black box, can be used for the evaluation and management of college students to provide data basis and reference.

\section{Create A Data Culture and Enhance the Quality of Data Awareness}

In the information age, it is the key to reduce the risks and mistakes and improve the efficiency of the various colleges and universities in order to develop the application of data consciousness and make decisions based on data. Starting from the practice, first to fundamentally guarantee the "number of active and reliable"; secondly, it is the definition and connotation of quality target data of related data, and establish a unified system of data quality, processing and effective supervision and the related data of the. For the implementation of specific work department data, you can consider the development of a common discourse system and standard definition and specific operational procedures, specific clear responsibilities of relevant departments, to realize the sharing and cooperation, the development of the business sector. Third, we should improve the ability of data mining, mining and analysis. This requires that each of the actors must know that the big data is not a data aggregation or data list, but the fine processing of data, data processing personnel should have data literacy. As the scholar Te Reni Azee (Terenzini) said, data processing technology and personnel necessary intelligent analysis (database management, statistical thinking and qualitative processing), intelligent college affairs (familiar with specific affairs, senior management staff met the function and decision-making procedures) and situational intelligence Colleges (familiar with college values and attitudes. The current trend of development, actuality and History) in three aspects.

\section{New Problems of College Students' Education MANAGEMENT UNDER THE NEW SITUATION}

\section{A. The Wealth Gap Caused by the Economic Situation}

From the international situation, in the context of economic globalization, the world's economic penetration. From the domestic situation, at present, our country is still in the primary stage of socialism, the state adheres to the basic economic system of public ownership, the common development of multi ownership economy, the basic economic system in the primary stage of socialism determines the distribution of personal income associated with this practice is the distribution system of distribution according to work is dominant and the coexistence of a variety of distribution mode. Since the reform and opening up, China's economic situation as a whole has developed well, forming a socialist economic system with Chinese characteristics, some people get rich first. With the rapid development of China's economy, private enterprises and foreign enterprises are increasing, and the overall economic situation is good. Enterprises in the interests of their own, in order to obtain more market resources, the fierce market competition, the enterprises in the growing process of mergers and acquisitions, the emergence of a large number of vacant posts, society needs talents. In order to meet the needs of the industry, colleges and universities have set up the hot spot of the current society

Industry. Students and parents in the professional choice, many are based on the current economic development situation of the popular professional choice, resulting in a short time in a rapidly increasing number of professional, and some professional relatively atrophy, thus, has changed the mentality of the students. Can enter a better employment prospects of professional students is their very superiority, some even thought to enter the professional dizzy with success, threshold ignored the growth and development of Everything will be fine., itself, leading to the final without any success. Enter the popular professional students, in the face of other popular professional students, often easy to cause such as jealousy, anxiety, self-esteem and other psychological problems, and even the emergence of the phenomenon of negative to muddle along. In addition, the gap between the rich and the poor, the family conditions are good students and families of poor students in the consumption, living conditions have formed a sharp contrast, greatly affected the healthy growth of students.

\section{B. The Question of The Rights and Interests Brought by the Political and Social Situation}

China is in the period of social transformation, facing many contradictions. After a long period of exploration and practice, China has gradually formed a set of policies and policies of socialism with Chinese characteristics. Since the college entrance examination system has been restored, the education has been paid more attention. The central government has put forward the strategy of "rejuvenating the country through science and education" and "talent power". China's illiteracy rate decreased year by year, after receiving a primary school, junior high school, high school education, especially after university enrollment, about 20 years old a lot of young people have the opportunity to enter the university to continue studying, the growing scale of College students. But with the enhancement of the national economic and social development and people's consciousness of democracy, the student family needs and students' self awareness, in relation to their own interests problems showing greater enthusiasm than in the past, the students began to consciously safeguard their own interests, take the initiative to express their interest demands. They are no longer satisfied with simply consider professional learning in the school, the school to put forward more and more problems, more and more directly, also will be more and 
more sharp, student education management is also increasing.

\section{The Diversity of Value Brought by Cultural Factors}

The influence of current social culture on College Students' educational management can not be ignored. With the development of industrialization and the rapid development of the society and the mechanism of the market economy, with the help of the mass media, in order to obtain commercial profit "products" for the purpose of serving the public consumption of entertainment "popular culture", has quietly come into our daily life, and to a certain extent affect the consumer orientation of the cultural life of the people and consumption.

\section{THE New Situation OF College StUdents EDUCATION MANAGEMENT COUNTERMEASURES}

Many problems in the new situation, put forward many new challenges to the management of college education, college students' education and management to take appropriate measures to solve the problems under the new situation, the education management of college students can not avoid the subject.

\section{A. Strengthening the Management of Student Status}

School management is an important part of college student management, it is the basis for the protection of school education smoothly, but also the specific behavior of students in school learning and life requirements. The scope of school management is more extensive, including the transfer of professional, transfer, etc.. The Ministry of education to turn professional, transfer and other aspects of the right to give a lot of colleges and universities, schools can be implemented in accordance with the specific provisions of the actual implementation of the specific management of students. Colleges and universities should take responsibility, establish a fair and impartial management system, especially in the transfer mechanism, turn professional hand to set up the survival of the fittest, let more excellent in character and learning students have more competition and choice, really stimulate the enthusiasm of students, and build a fair and harmonious campus.

\section{B. To Establish a New Management Concept}

In the process of the innovation of the management system, the management of colleges and universities should abandon some of the old ideas in the original management idea, and then introduce some excellent ideas of educational management. School leaders should have the courage to innovate management ideas, to improve the overall quality of students as the starting point of education, put forward the concept of school characteristics, and constantly lead the school reform and development, the formation of a good ecological education. On the one hand, school managers should pay attention to the all-round development of students, to be good at students' minds, really anxious students are anxious, want to students to think, to be good at listening to the views of students, respect students' personality, cultivate students' comprehensive ability; on the other hand, education administrators should actively adapt to the new normal education under and to improve the students' literacy, improve the quality of students, cultivate students' morality, really put the students into the independent individuality, personal integrity, noble character, know as qualified citizens. In addition, to actively explore the implementation of fine management of University, construction of the fine management system of school running, to meet the students needs as a starting point, do the management of the school education into practice.

\section{To Strengthen College Students' Moral Education Moral Education is the Fundamental Task of Universities. Universities Should Strive}

To strengthen the moral education team construction, deepen the management of moral education, moral education to expand the space, efforts to strengthen the students' habits of education, strengthen the training of students' daily behavior habits, promote students to develop good habits. Colleges should make full use of various forms of activities, stages will be implemented by the theme of moral education, guide students to love the collective, the students love, love the teacher, love their parents, foster and learn how to correctly handle the individual and collective interests, honest, trustworthy, do. At the same time, colleges and universities should cultivate students' sense of responsibility, service consciousness and actively participate in social public affairs, and exercise their ability of self-management, self-education and initiative development.

\section{SUMMARY}

At present, there are many problems in the management of education in Colleges and universities in our country. We insist on reform and innovation, which will be effective. In order to improve the quality of education for the purpose of improving the management level as a means for teaching is not empty, let students have the ability to cultivate highquality talents, social needs for oneself, continuously push forward the reform and innovation of educational management concepts and educational management system.

\section{REFERENCES}

[1] Li Xin. The application of the concept of "people first" in higher education management [J]. Journal of China Three Gorges University (HUMANITIES AND SOCIAL SCIENCES EDITION), 2015

[2] Yin Liping. Discussion on [J]. industry and science and Technology Forum of information management in Colleges and universities, 2012

[3] [J]. Chinese Guo Wujun. Thinking of adult education management innovation in higher education, 2007

[4] The present situation, problems and Countermeasures of the development of the theoretical community in Colleges and universities [J]. Chen Lei, Han Hui Wei. Chinese school education. 2013 (36). 